\title{
Interweaving EFL Learners' Speaking, Reading, Writing Strategies and Epistemic Beliefs to Language Achievement through E-Learning
}

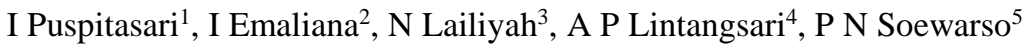 \\ $1,2,3,4,5$ Universitas Brawijaya, ${ }^{3}$ Universitas Negeri Malang
}

\{ikapuspitasari@ub.ac.id\}

\begin{abstract}
The use of strategies in learning is believed to lead the way for success among students. Thus, there have been various learning strategies that surface from several causes such as the ones triggered by the teachers through the teaching techniques employed in the classroom and/or the ones owned by the students themselves. In the context of EFL in Indonesia, learning strategy is an interesting issue to discuss especially the ones dealing with the language skills with the notion that good language skills mastery might affect students' success in other areas as well. Albeit, the strategy of learning can be triggered by their beliefs in learning which is under the theory of epistemic beliefs. It is the belief that the students hold concerning their understanding in defining learning English and ways to learn English. In a bid to expand the body of research on learning strategies for English achievement, this study investigated speaking, reading, and writing strategies and their relationship with EFL epistemic beliefs, for little research has specifically explored the dynamic nature of learning beliefs. To address this gap, robust theoretical framework to develop a causal model hypothesis needs to reveal. Through library research causal relationships among speaking, reading, writing, epistemic beliefs and achievement are formulated. In the light of these findings, the researchers propose pedagogical implications for EFL teaching and learning theory, method, and practice.
\end{abstract}

Keywords: Speaking Strategy, Reading Strategy, Writing Strategy, Epistemic Beliefs, E-Learning, Achievement

\section{INTRODUCTION}

It is inevitable that strategy plays a focal role in learning as it offers help to learners to be able to succeed in their learning especially in the digitalized era when learning can be done online or with the assistance of technology. Strategy in learning has long been a focus of investigation as it serves as one of the contributors as to whether the language learning is successful or not[1]. Oxford [2] states that strategies in learning are crucial for the learning of a language because they serve as tools which facilitate active and self-triggered involvement. It is then evident that learning strategy is able to initiates autonomy in learning a language and in turn it will promote achievemnt in language proficiency.

Nowadays there has been quite a shift in the education where learning is no longer traditionally done where teachers are dominant in the teaching and learning process. It is to say 
that learners were somewhat spoonfed and relied heavily on the presence of teachers. Since the trends have changed, technology has somehow provide a lot of assistance both to teachers and learners. Thus, it is necessary that learners are aware of their needs in response to the development of technology in education. Each individual learner must then have their own strategy. Unfortunately, some learners do not seem to realize they have their own so that they are not yet able to maximize theirs so that their learning is not yet efficient.

Learning strategies can be the ones which are triggered by the teachers who introduce them to learners by emploing certain techniques during the teaching and learning process. Learning strategies are also closely related to students' beliefs which are best known as epistemic beliefs which are 'individual's beliefs about knowldege and knowing'[3]. Then, epistemic beliefs can be used, among others, to determine learning strategies which in turn will affect the achievement in language learning.

Various studies have previously been conducted in sheding the lights on strategies of language learning in many aspects especially language skills such as reading, writing, and speaking. Yet, the research was done in discrete. Thus, this current research was intended to propose possible relation among reading strategy, writing strategy, speaking strategy, epistemic beliefs, and language achievement through e-learning.

\section{RESEARCH METHOD}

This paper is a literature review by design. Thus, it was conducted by investigating books and several scholarly journals which presented summaries, descriptions, and overview in regards with the research problems being studied. Literature review is specifically intended to provide overview over sources on particular topics being invesitaged in order to reveal the contribution and correlation of current research with a larger field of study.

\section{RESULTS AND DISCUSSION}

\subsection{Reading Strategy}

Reading is one of the receptive skills in language that is perceived as very important. It is through reading that learners are much exposed to new knowledge of language. Consequently, learners are expected to have good proficiency as an attempt to avoid misunderstanding of texts which are caused by several factors such lack of vocabulary mastery and cultural differences. There have been many research conducted to investigate leraners' problems in reading and the strategy used or that can be employed by learners in overcoming the problems.

Experts have formulated solution to those reading problems. One of them is on the use of reading strategies which improve comprehension on reading and make reading activity more effective. Sheorey and Mokhtari [4] indicate that reading strategies fall into three classification, they are metacognitive, cognitive and supportive. Metacognitive strategies in reading are defined as techniques which are intentionally employed by learners in order to check and manage their reading. Cognitive strategies refer to the actions taken or procedures done by learners when they are working with a reading text. Meanwhile, support strategies are strategies in involving tools such as by using dictionary, or other devices for highlighting text or in taking notes in a quest to comprehend the text.

Mokhtari and Reichard [5] have been working further with the strategies in reading. They add more classifications on reading strategies by including global reading strategies (GLOB), problem-solving strategies (PROB), and support strategies (SUP). GLOB are strategies that 
incorporate determining purposes of reading, activating schemata, investigating the congruence of purpose and content of the text, and making prediction on what the text is about.

\subsection{Speaking Strategy}

As one of productive skills, speaking in English has also been considered as another crucial skill to master. Moreover, the world has witnessed the importance of communication, be it in oral or written forms, that the spotlight has directed to the investigation on strategies used by learners in speaking. It is somewhat in response to the shift in the approach being held currently in education when communicative approach has become the main references in the teaching of English in Indonesian context.

Some learners find that speaking is not an easy task to do. Teachers have identified the problems as well as they have the experiences of being in the classroom teaching the subject. Thus, strategies are needed. Similar with the case in reading, strategies have also been identified and formulated by experts. Huang [6] indicates that speaking strategies are categorized into three which are cognitive strategy, communicative strategy, and affective strategy. In cognitive strategies, learners are processing the information inductively, performing the analysis, and organizing thoughts when learning to speak. Meanwhile, communication strategies are done by elaborating and reducing the information when necessary, as well as restructuring the information in order to be able to get the message accross. The third is affective strategies. As its name suggests, affective strategies deal with affective factors. In applying the trategies, learners tend to encourage calm, and comfort themselves when problems occur.

\subsection{Writing Strategy}

Strategies in writing play important roles for learner striving to master writing skill. Writing might be challenging as it takes more than one stage to complete as writing emphasized more on the process than product especially in the area of academic writing. Basically, the strategies are somewhat similar to the ones implemented in other skills. Hwang[6] indicates that writing strategies consist of metacognitive, cognitive, and affective. Those three strategies are employed when learners are in the mids of working on their writing which consist of several stages which are pre-writing, whilst-writing, and post-writing.

Writing strategies come into use when learners are exposed to problems in writing. Those problems range from finding ideas, to organizing ideas because writing is bound to certain genres which require specific organization as well. Having the problems in

\subsection{Epistemic Belief}

Epistemic beliefs which was originated from the word epistemology essentially falls into the area of educational psychology. In this area of educational phychology, there have been two bases of study concerning on epistemic beliefs that can be correlated to Piaget's work on consideration of epistemology on genetic and also that of Pery concerning epistemological development identified to be prevalent on students of higher education [7]. Piaget has reveived a lot of attention on his works and many of them become the references for many studies. Muis [8] believe that Piaget's theory on cognitive development was driven by problem of knowledge that is commonly called as epistemological problem. This problem is somewhat closely related with and cannot be taken off of the development of intelligent. Meanwhile, Perry identified that there are manifold probabilities for knowledge to be perceived by students after several years 
being exposed to diverse intellectual and social settings of higher education [7]. Muis [8] believes that those two notions were focused on the knowledge's nature and beliefs' justification, which represent epistemology, as an offshoot of philosophy. Phylosophy and educational psychology have become concern for some parties that numerous research have been conducted which involved different definitions, theoretical frameworks, and methodologies in a pursuit of exploring epistemic beliefs held by learners.

However, Bräten \& Strømsø [9] state that epistemic beliefs have not been the only focus in educational psychology. Instead, the attention was also given to other disciplines such as higher education [10], reading and literacy [9], science education [11], and CALL [12]. Each of those previously mentioned research employed different methods and paradigms. Consequently, the results of the research reflected the condition of different locations and have been exploited for different constructs [8].

Related to the research on epistemic beliefs and the learning of English language, there has not been any specific theoretical framework used as reference. Whether or not the research on epistemic beliefs has correlation to the first language learning (such as the one found in Fujiwara et al. [10], Chen [13], and Franco et al. [14]), the empirical findings resulted from those studies have indicated that university students hold specific epistemic beliefs concerning the targer of foreign language learning especially when it comes to the EFL setting. Those beliefs signify that better EFL learning proficiency is somewaht resulted from higher epistemic beliefs held by those learners. Yet, it is worth noting that the previous studies were not specifically concerned on the learning of English.

In view of that, general epistemic beliefs should be adjusted with EFL's beliefs in order to accomodate EFL epistemic beliefs. Theories on epistemic beliefs which explain two variables, which are what the knowledge is and how to acquire knowledge, specify that there are some dimensions constructing epistemic beliefs of EFL. There are three dimensions under the first variable which is what knowledge is. Those dimensionas are certain knowledge, simple knowledge, and nature of language learning. Meanwhile, the second variable which concerns on how the knowledge is acquired, is comprised on seven dimensions which are fix ability, quick learning, omniscent authority, the language learning difficulty, foreign language aptitude, strategies in learning and communication, and motivation and expectation. Emaliana [15] developed those EFL epistemic beliefs constructs.

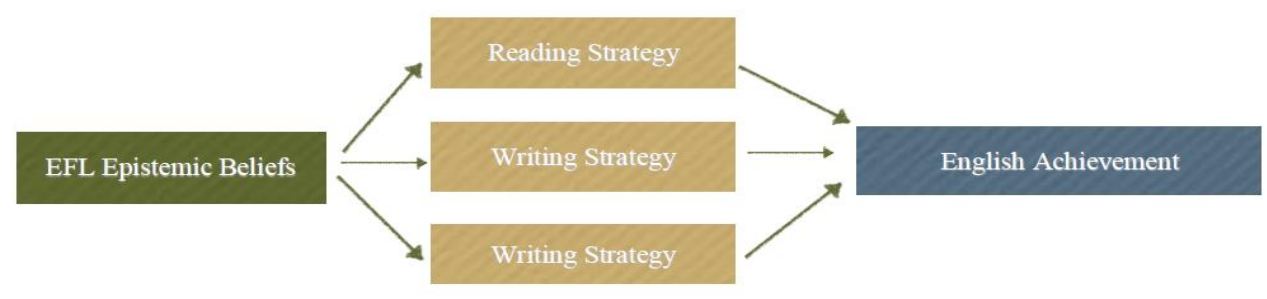

Figure1. Model hypothesis of causal relationship among Reading, Writing, Speaking strategies, EFL Epistemic Beliefs, and English achievement.

Having all the strategies of reading, speaking, and writing, and epistemic beliefs explained, the proposed model hypothesis of causal relationship among the elements are described as above. EFL epistemic beliefs have significant contribution to learners use of strategies in 
reading, speaking, and writing. The students beliefs on how they learn certainly trigers learners to find ways out whenever they are in difficulties. This is done by utilizing any strategies matching their need and personalities. When strategies are employed at their best, the learners will earn abundant benefits in learning. Thus, they will get good achievement in language learning that is proven by the ability to comprehend and use it for all forms of communication [16].

\section{CONCLUSIONS}

Learning strategies have great impact in learning. Learners need strategies to be able to succeed in learning and have great achievement. Learning strategies can be introduced and promoted by teachers by means of teaching technique employed during the teaching and learning process, and they can also self-inflicted. The use of learning strategies is much affected by the beliefs that the learners own. It is wellknown as epistemic beliefs which is the beliefs of the learners on knowledge and knowing. Their beliefs determine what strategies to use and to eliminate based on the needs. In turn, strategies can further lead learners to achieve success in learning as strategies help learners deal with difficulties they encounter. It is then evident that epistemic beliefs, learning strategies for reading, speaking, and writing, along with learning achievement are closely related and affect one another.

\section{REFERENCES}

[1] A. Abedini, A. Rahimi, and A. Zare-ee, "Relationship between Iranian EFL Learners' Beliefs about Language Learning, their Language Learning Strategy Use and their Language Proficiency," Procedia - Soc. Behav. Sci., vol. 28, pp. 1029-1033, 2011.

[2] R. Oxford, Language Learning Strategies: What every teachers should know. Boston, Massachusetts: Heinle \& Heinle Publishers.

[3] F. Berding, K. Rolf-Wittlake, and J. Buschenlange, "Impact of Different Levels of Epistemic Beliefs on Learning Processes and Outcomes in Vocational Education and Training," World J. Educ., vol. 7, no. 3, p. 12, 2017.

[4] K. Mokhtari and R. Sheorey, Reading strategies of first and second language learners: see how they read. Norwood: Christopher-Gordon Publisher.

[5] K. Mokhtari and C. A. Reichard, “Assessing students' metacognitive awareness of reading strategies.," J. Educ. Psychol., vol. 94, no. 2, pp. 249-259, 2002.

[6] H.-T. D. Huang, "Exploring strategy use in L2 speaking assessment," System, vol. 63, pp. 13-27, Dec. 2016.

[7] J. T. E. Richardson, "Epistemological development in higher education," Educ. Res. Rev., vol. 9, pp. 191-206, Jun. 2013.

[8] K. R. Muis, "Personal Epistemology and Mathematics: A Critical Review and Synthesis of Research," Rev. Educ. Res., vol. 74, no. 3, pp. 317-377, Sep. 2004.

[9] I. Bråten and H. I. Strømsø, "Epistemological beliefs and implicit theories of intelligence as predictors of achievement goals," Contemp. Educ. Psychol., vol. 29, no. 4, pp. 371-388, Oct. 2004.

[10] T. Fujiwara, P. Laulathaphol, and B. J. Phillips, "Thai University Students' Scientific Epistemic Beliefs: Relationships with Past Learning Experiences," Procedia - Soc. Behav. Sci., vol. 69, pp. 187-196, Dec. 2012. 
[11] C. Tsai, "Conceptions of learning science among high school students in Taiwan: a phenomenographic analysis," Int. J. Sci. Educ., vol. 26, no. 14, pp. 1733-1750, Nov. 2004.

[12] L. Mason, N. Ariasi, and A. Boldrin, "Epistemic beliefs in action: Spontaneous reflections about knowledge and knowing during online information searching and their influence on learning," Learn. Instr., vol. 21, no. 1, pp. 137-151, Feb. 2011.

[13] J. A. Chen, "Implicit theories, epistemic beliefs, and science motivation: A personcentered approach," Learn. Individ. Differ., vol. 22, no. 6, pp. 724-735, Dec. 2012.

[14] G. M. Franco, K. R. Muis, P. Kendeou, J. Ranellucci, L. Sampasivam, and X. Wang, "Examining the influences of epistemic beliefs and knowledge representations on cognitive processing and conceptual change when learning physics," Learn. Instr., vol. 22, no. 1, pp. 62-77, Feb. 2012.

[15] I. Emaliana and N. Lailiyah, "SOPHISTICATED EPISTEMIC BELIEFS: AN INTERPRETATIVE PHENOMOLOGICAL ANALYSIS OF STUDENTS' TASKBASED LEARNING EXPERIENCES," Erud. J. Educ. Innov., vol. 5, no. 1, pp. 124-135, Jul. 2018.

[16] K. Saddhono, "Integrating Culture in Indonesian Language Learning for Foreign Speakers at Indonesian Universities." J. of Lang. and Lit. vol. 6 no.2 pp. 349-353, 2015 